\title{
SUSTAINABILITY LIFE CYCLE DESIGN OF BRIDGES IN AGGRESSIVE ENVIRONMENTS CONSIDERING SOCIAL IMPACTS
}

\author{
IGNACIO J. NAVARRO ${ }^{*}$, VÍCTOR YEPES ${ }^{2 \dagger} \&$ JOSÉ V. MARTÍ $^{2 \ddagger}$ \\ ${ }^{1}$ Department of Construction Engineering, Universitat Politècnica de València. \\ ${ }^{2}$ Institute of Concrete Science and Technology (ICITECH), Universitat Politècnica de València.
}

\begin{abstract}
The establishment of the Sustainable Development Goals in 2015 claims for a deep paradigm shift in the way infrastructure structures are conceived. The evaluation of the impacts derived from the construction, the service and the end-of-life stages of an infrastructure is consequently in the spotlight of the research community. Being the construction sector as one of the main stressors of the environment, great attention has been recently paid to the structural design from the economic and the environmental point of view. However, sustainability requires to consider the social dimension as well. The evaluation of the social impacts of products is still at a very early stage of development, so the inclusion of social aspects in the design of structures is often overlooked. In this study, a comparison of life cycle assessment results is conducted on seven different design alternatives for a bridge in a coastal environment. Two approaches are followed: the first approach considers the economic and the environmental aspects of each design and the second approach includes the several social impacts specifically developed for the assessment of infrastructures. These social impacts account for four stakeholders, namely workers, consumers, local community and society. Results show that the inclusion of social aspects shall lead to different preferred options when compared with conventional, two-dimensional approaches. Here, the design with silica fume added concrete performs $11 \%$ better from a sustainability point of view when compared with the best solution resulting from a conventional assessment.
\end{abstract}

Keywords: AHP, bridges, corrosion, life cycle assessment, maintenance, multi-criteria decision-making, reliability, social impacts, sustainability, sustainable design.

\section{INTRODUCTION}

The 17 Sustainable Development Goals (SDGs) call for a change in the way the society interacts with the world today. Such goals are meant to achieve challenging objectives such as guaranteeing justice and equity for all, reducing poverty or avoiding climate change. In such context, it can be surprising that the design of sustainable infrastructures has made its way to be the ninth SDG. In fact, the design of sustainable infrastructures is recognised to be a key goal to help in achieving the others. Such statement is based on the fact that the construction sector is one of the main stressors of the environment $[1,2]$. In addition, the economic rele-

* ORCID:https://orcid.org/0000-0002-6539-1626

$\dagger$ ORCID: https://orcid.org/0000-0001-5488-6001

† ORCID: https://orcid.org/0000-0002-2435-4095 
vance of the construction and maintenance of infrastructures is out of doubt. An example of this is the fact that about $20 \%$ of World Bank loans in recent years have been allocated only to transport infrastructure [3].

Consequently, research has been conducted over the past recent years on reducing the environmental and economic impacts of structures along their life cycle. Efforts have been made on optimising infrastructure designs to find cost-effective solutions [4-6], as well as to find the optimal maintenance intervals from an economic perspective [7-8]. Research has also been recently conducted on finding designs that minimise environmental impacts derived from construction [9] and maintenance of infrastructures [10-12]. However, less has been investigated on the positive social impacts derived from the construction and maintenance of infrastructures, which are related to the economic development of regions, accessibility to services or employment generation, among others [13-15].

Because of the above criteria, very little has been written on the simultaneous consideration of not only environmental and economic design criteria but also the social impacts derived from infrastructures when assessing their sustainability performance. Sustainability assessments of structures are, therefore, usually made paying attention to the better known economic and environmental aspects [16-18]. After the establishment of the SDGs, more attention has been paid to three-dimensional approaches, including social aspects [19]. However, those recent assessments usually only consider a rather simplistic view of social impacts, including aspects such as aesthetics, impacts on users or the health and safety of the workers. These assessments disregard other relevant social impacts associated to the construction, maintenance and demolition of infrastructures, which are more aligned with the achievement of the SDGs, such as gender issues, employment generation, poverty reduction, accessibility or others.

This article aims to analyse how the economic, environmental and social impacts are related along the different life cycle stages of a bridge structure in a maintenance demanding location. A comparison is made on how sustainability assessment results are modified when including SDG-oriented social aspects in the life cycle analysis of a structure.

\section{RESEARCH METHODOLOGY}

\subsection{Sustainability assessment of bridge designs}

Both the conventional approach and the holistic approach to the sustainable assessment of structural designs require the analysis of each dimension to be consistent with each other. The environmental standards ISO 14040 and ISO 14044 provide a powerful methodology to conduct rigorous and transparent life cycle assessments from the environmental perspective. However, it is not until 2009 when an ISO 14040-based framework for the social life cycle assessment of products is developed [20].

Here, the assessment of the three dimensions is performed following these guidelines so as to make each analysis comparable. So, according to ISO 14040, a life cycle assessment shall consist of four steps, namely a definition of the goal and scope of the study, a clear analysis of the inventory, the description of the methods and hypotheses assumed for the life cycle assessment, and at last the presentation and discussion of the obtained results.

\subsubsection{Goal and scope definition}

The goal of the present analysis is to compare the sustainability performance of different bridge designs conceived as alternatives to a baseline case study. This so-called hereafter reference design (REF) is assumed to be a continuous prestressed concrete bridge deck located 
Table 1: Concrete mixes assumed for each design.

\begin{tabular}{llllll}
\hline Mix component & REF & SF10 & FA20 & PMC10 & W/C35 \\
\hline Cement $\left(\mathrm{kg} / \mathrm{m}^{3}\right)$ & 350 & 280 & 329 & 350 & 350 \\
Water $\left(1 / \mathrm{m}^{3}\right)$ & 140 & 140 & 140 & 140 & 122.5 \\
Gravel $\left(\mathrm{kg} / \mathrm{m}^{3}\right)$ & 1,017 & 1,017 & 1,017 & 1,017 & 1,037 \\
Sand $\left(\mathrm{kg} / \mathrm{m}^{3}\right)$ & 1,068 & 1,129 & 1,086 & 1,068 & 1,095 \\
Fly ash $\left(\mathrm{kg} / \mathrm{m}^{3}\right)$ & - & - & 70 & - & - \\
Silica fume $\left(\mathrm{kg} / \mathrm{m}^{3}\right)$ & - & 35 & - & - & - \\
Latex $\left(\mathrm{kg} / \mathrm{m}^{3}\right)$ & - & - & - & 35 & - \\
Plasticiser $\left(\mathrm{kg} / \mathrm{m}^{3}\right)$ & 5.3 & 4.2 & 4.9 & - & 7 \\
\hline
\end{tabular}

in a coastal region in northern Spain, namely in Pontevedra. The bridge has a box-girder deck and is $2 \times 40 \mathrm{~m}+38 \times 50 \mathrm{~m}=1,980 \mathrm{~m}$ long. The conventional concrete mix on which this design is based is provided in Table 1 .

There exist several ways to enhance the response against chloride-induced corrosion of conventional concrete designs. Here, six alternative designs are analysed. Three of them base their durability in the reduction of the concrete porosity through including additions to the baseline concrete mix. So, alternative SF10 consists of adding $10 \%$ silica fume to the concrete mix, FA20 consists of adding 20\% fly ash, and PMC10 consists of adding $10 \%$ styrene butadiene latex. In the case of SF10 and FA20, the cement content has been partially replaced to provide a concrete with the same compressive strength as the baseline mix. Another way to reduce porosity is by simply reducing the water/cement ratio. In this case, alternative W/C35 consists of reducing the reference water/cement ratio of 0.40 to 0.35 . The resulting concrete mixes for these alternative solutions are presented in Table 1 . To provide better resistance against corrosion, conventional carbon steel for passive reinforcements shall be substituted by stainless steel (alternative INOX hereafter). At last, a usual way to act against corrosion without modifying neither the steel nor the concrete mix of the baseline design consists of isolating the deck from chlorides through a hydrophobic surface treatment (alternative HYDRO hereafter), thus preventing the ingress of aggressive agents into the concrete cover.

The assessments shall be based on the same functional unit to make results comparable, according to ISO 14040. Here, impacts are evaluated along the life cycle of a 1-m-long section of the described bridge deck, offering a route connection over a service life of 100 years. To evaluate the impacts derived from both construction and maintenance activities, a 'gate to grave' approach has been considered.

In order to determine the maintenance demands of each alternative under study, a two-dimensional version of the Fickean model included in Fib Bulletin 34 [21] has been used to evaluate the advance of the chloride ingress in concrete over time. A surface chloride concentration $C_{s}=0.33 \%$ and an age factor $\alpha=0.5$ have been assumed according to Spanish concrete standard EHE-08. The assumed concrete cover is $40 \mathrm{~mm}$ for every alternative. To find the maintenance interval that maximises the sustainability response of each alternative, a target reliability shall be chosen. Here, maintenance activities shall be held before the reliability $\beta(t)$ reaches $\beta_{\text {lim }}=1.3$ [22]. The evolution of the structural reliability over time is evaluated by 
Table 2: Durability characterisation of each design [23].

\begin{tabular}{llllll}
\hline $\begin{array}{l}\text { Design } \\
\text { alternative }\end{array}$ & \multicolumn{2}{c}{$\mathbf{D}_{\mathbf{0}}\left(\times \mathbf{1 0} \mathbf{1 0}^{\mathbf{- 1 2}} \mathbf{~ m}^{\mathbf{2}} / \mathbf{s}\right)$} & \multicolumn{2}{c}{$\mathbf{C}_{\text {crit }}(\boldsymbol{\%})$} & $\begin{array}{l}\text { Maximum allowable } \\
\text { maintenance interval }\end{array}$ \\
\hline REF & SD & Mean & SD & 8 years \\
SF10 & 1.90 & 0.90 & 0.60 & 0.10 & 90 years \\
FA20 & 4.65 & 0.17 & 0.60 & 0.03 & 25 years \\
PMC10 & 6.51 & 0.55 & 0.60 & 0.10 & 10 years \\
INOX & 8.90 & 0.90 & 5.00 & 0.94 & No maintenance needed \\
W/C35 & 5.80 & 0.47 & 0.60 & 0.10 & 17 years \\
HYDRO & 6.88 & 0.60 & 0.60 & 0.10 & 5 years \\
\hline
\end{tabular}

means of Monte Carlo simulations, taking into consideration the statistical characterisation of the durability parameters included in Table 2.

\subsubsection{Impact assessment}

For the assessment of the environmental dimension, the ReCiPe 2008 methodology [24] is followed to obtain environmental impacts on human health, ecosystems and availability of natural resources. Regarding economic impacts, the costs associated to both the construction and the maintenance phase are considered here. Maintenance costs are discounted using a social discount rate of $d=2 \%$. More information on the environmental and economic assessment shall be found in Navarro et al. [7].

Social impacts are assessed following the impact methodology proposed in Navarro et al. [13]. To assess the social impacts, the first step is to determine the stakeholders that might be affected by the structure under assessment [20]. This indicator-based methodology bases the assessment on the impacts generated on the four main stakeholders associated to bridge infrastructures in Spain, namely workers, users, local economies and local non-users. The identification of such stakeholders is based on a hotspot analysis [25] of the regional development plan related to the installation site of the bridge (Pontevedra, Spain). The social impact on workers considers a set of four indicators, namely the generation of employment, the discrimination of gender, the safety of the working conditions and the salary. The indicator on the local employment generation is defined as follows:

$$
X_{\text {local empl }}=\frac{u r-U r_{\min }}{U r_{\max }-U r_{\min }}
$$

where $u r$ stands for unemployment rate at the activity location, $U r_{\min }$ stands for minimum national unemployment rate and $U r_{\max }$ is the maximum national unemployment rate. The gender discrimination indicator is defined as follows:

$$
X_{\text {gender disc. }}=0.5 \cdot \min \left\{1-\left|\frac{U r_{m}}{U r_{\text {mean }}}-1\right| ; 1-\left|\frac{U r_{w}}{U r_{\text {mean }}}-1\right|\right\}+0.5 \cdot \min \left\{1-\left|\frac{S_{m}}{S_{\text {mean }}}-1\right| ; 1-\left|\frac{S_{w}}{S_{\text {mean }}}-1\right|\right\}
$$

where $U r_{m}$ is the men's unemployment rate, $U r_{w}$ stands for women's unemployment rate, $U r_{\text {mean }}$ is the mean unemployment rate, $S_{m}$ is the men's mean salary, $S_{w}$ stands for women's 
mean salary and $S_{\text {mean }}$ is the mean salary. All these rates are related to the specific activity location. The indicator for the working conditions of each activity is obtained as follows:

$$
X_{\text {safety }}=1-\frac{a r-A r_{\text {min }}}{A r_{\text {max }}-A r_{\text {min }}}
$$

where $a r$ is the accident rate, $A r_{\text {min }}$ is the minimum national accident rate and $A r_{\text {max }}$ stands for the maximum national accident rate. Again, all these rates are linked to the specific activity location. At last, the salary fairness can be measured as follows:

$$
X_{\text {salary }}=\frac{s-S_{\min }}{S_{\max }-S_{\min }}
$$

where $s$ stands for the mean salary for the specific activity at the activity location, $S_{\min }$ is the national living wage and $S_{\max }$ is the maximum national salary for the specific activity.

Regarding the social impacts on the local economies affected by the activities required to materialise the functional unit under study, the following indicator is used:

$$
X_{\text {local economy }}=\left(1-\frac{g d p-G D P_{\min }}{G D P_{\max }-G D P_{\min }}\right)
$$

where $g d p$ is the gross domestic product at the activity location, $G D P_{\min }$ is the minimum national gross domestic product and $G D P_{\max }$ stands for the maximum national gross domestic product.

The impact on users shall be evaluated by means of how maintenance affects the accessibility and their travel safety. The impact on the accessibility can be evaluated as follows:

$$
X_{\text {accesibility }}=\frac{\left(T_{S L}-\sum t_{m}\right) \cdot 1+\sum t_{m} \cdot a}{T_{S L}}
$$

where $T_{S L}$ is the bridge service life, $\Sigma t_{m}$ is the total time that the bridge is under maintenance and $a$ is the ratio between traffic speed under maintenance and normal operation circumstances. The impact on user's safety shall be quantified as follows:

$$
X_{\text {user's safety }}=1-\frac{l}{L_{\text {tot }}} \cdot \frac{\sum t_{m}}{T_{S L}} \cdot \frac{v}{V_{\text {norm }}}
$$

where $l$ is the length of the maintenance work zone, $L_{\text {tot }}$ is the bridge total length, $v$ stands for the traffic speed under maintenance operations along the work zone and $V_{\text {norm }}$ is the traffic speed under normal operation conditions.

At last, the indicator used to evaluate the social impact of the bridge's maintenance demands on the public opinion can be expressed as follows:

$$
X_{\text {public opinion }}=1-R T U A=1-\frac{\sum t_{m}}{T_{S L}}
$$

where RTUA stands for the relative time of unsatisfactory appearance.

\subsubsection{Inventory analysis}

According to ISO 14040, the data needed to perform the life cycle assessment, in this case the data required to characterise the economic, environmental and social dimensions, shall be gathered from accepted sources. Here, the economic data to assess the costs along the life 
Table 3: Production and installation costs of materials.

\begin{tabular}{|c|c|c|c|c|c|c|}
\hline Product & Cement & Concrete & Additives & Steel & $\begin{array}{l}\text { Surface } \\
\text { treatment }\end{array}$ & Installation \\
\hline $\mathrm{m}^{3}$ Baseline concrete & $30.7 €$ & $31.7 €$ & - & - & - & $31.6 €$ \\
\hline $\mathrm{m}^{3} \mathrm{~W} / \mathrm{C} 35$ concrete & $30.7 €$ & $32.4 €$ & - & - & - & $36.7 €$ \\
\hline $\mathrm{m}^{3} \mathrm{FA} 20$ concrete & $43.4 €$ & $34.6 €$ & - & - & - & $31.1 €$ \\
\hline $\mathrm{m}^{3} \mathrm{SF} 10$ concrete & $36.9 €$ & $72.4 €$ & - & - & - & $30.1 €$ \\
\hline $\mathrm{m}^{3} \mathrm{HMP} 10$ concrete & $46.1 €$ & $31.7 €$ & $173.6 €$ & - & - & $24.3 €$ \\
\hline kg Carbon steel & - & - & - & $0.9 €$ & - & $0.4 €$ \\
\hline kg Stainless steel & - & - & - & $4.9 €$ & - & $0.4 €$ \\
\hline $\begin{array}{l}\mathrm{m}^{2} \text { HYDRO } \\
\text { treatment }\end{array}$ & - & - & - & - & $2.9 €$ & $1.6 €$ \\
\hline $\begin{array}{l}\mathrm{m}^{2} \text { Cover } \\
\text { hydrodemolition }\end{array}$ & - & - & - & - & - & $27.7 €$ \\
\hline $\begin{array}{l}\mathrm{m}^{2} \text { Reinforcement } \\
\text { preparation }\end{array}$ & - & - & - & - & - & $16.0 €$ \\
\hline
\end{tabular}

cycle of each of the alternatives under study have been collected from official Spanish construction-specific databases. Unitary costs for each economic concept are presented in Table 3.

Costs have been splittered depending on the production centre involved, as this will have an effect on the social impact regarding the economic development of local regions, as exposed earlier. Five different Spanish production centres are involved in the product system assumed here. Cement, fly ash and silica fume are produced in Coruna, as well as the carbon steel reinforcement. Polymers for PMC10 are produced in Madrid, while surface treatments are produced in Guadalajara. Concrete is produced in Pontevedra, where the bridge under analysis is located as well. At last, stainless steel is produced in Vizcaya.

The environmental database Ecoinvent 3.2 [26] has been considered to gather the inventory data for the environmental assessment of each of the alternatives under study. This information has been complemented with data regarding the machinery performance values and consumption rates, as shown in Table 4.

To evaluate the social impacts, every activity included within the boundaries of the product system under study shall be adequately characterised, particularising each of the social parameters considered in the assessment method described earlier depending on the particular activity and its location (Table 5). Social data have been gathered here from the Spanish Tax Office and the Spanish National Statistics Institute.

\section{RESULTS AND DISCUSSION}

\subsection{Economic performance results}

Here, the economic impacts along the life cycle of each alternative are presented (Fig. 1). Economic impacts are presented for both the construction phase and the so-called Rest of Life (RoL) phase, which includes maintenance and demolition life cycle stages. Results are 
Table 4: Demand values related to activity processes, based on Navarro et al. [27].

\begin{tabular}{lll}
\hline Process & Energy demand & Activity performance \\
\hline Concrete mixing & $75 \mathrm{~kW}$ & $7.2 \mathrm{~min} / \mathrm{m}^{3}$ \\
Emulsion mixing & $0.025 \mathrm{kWh} / \mathrm{kg}$ & \\
Hydrophobic surface treating & $1.3 \mathrm{~kW}$ & $120 \mathrm{l} / \mathrm{h}$ \\
Hydrodemolition & $0.75 \mathrm{~kW}$ & $0.6 \mathrm{~m}^{3} / \mathrm{h}$ \\
Sandblasting & $2.31 \mathrm{fuel} / \mathrm{h}$ & $13.2 \mathrm{~m}^{2} / \mathrm{h}$ \\
Shotcreting & $26.5 \mathrm{~kW}$ & $18 \mathrm{~m}^{3} / \mathrm{h}$ \\
\hline
\end{tabular}

Table 5: Inventory data for the social characterisation of the production centres involved, based on Navarro et al. [23].

\begin{tabular}{|c|c|c|c|c|c|}
\hline Socioeconomic concept & Pontevedra & A Coruña & Vizcaya & Madrid & Guadalajara \\
\hline Unemployment rate & $16.8 \%$ & $13.9 \%$ & $12.5 \%$ & $12.4 \%$ & $14 \%$ \\
\hline Men unemployment rate & $15 \%$ & $12.5 \%$ & $11.8 \%$ & $11.6 \%$ & $12.2 \%$ \\
\hline $\begin{array}{l}\text { Women unemployment } \\
\text { rate }\end{array}$ & $19.1 \%$ & $15.8 \%$ & $13.4 \%$ & $13.3 \%$ & $16.7 \%$ \\
\hline Salary (€/year) & $\begin{array}{l}19,600^{1} \\
14,300^{2}\end{array}$ & 19,600 & 20,300 & 32,000 & 23,600 \\
\hline Men salary (€/year) & 18,800 & 20,900 & 28,200 & 27,400 & 21,900 \\
\hline Women salary (€/year) & 14,200 & 15,900 & 20,100 & 20,100 & 16,000 \\
\hline $\begin{array}{l}\text { Mean regional salary } \\
(€ / \text { year) }\end{array}$ & 16,700 & 18,600 & 24,600 & 24,000 & 19,400 \\
\hline $\begin{array}{l}\text { Accident rate (per } 1000 \\
\text { workers) }\end{array}$ & $84^{2} ; 76^{3}$ & $95^{4} ; 73^{3}$ & 94 & 33 & 54 \\
\hline $\begin{array}{l}\text { Max. national accident } \\
\text { rate (per } 1000 \text { workers) }\end{array}$ & $111^{2} ; 100^{3}$ & $129^{4} ; 100^{3}$ & 129 & 55 & 55 \\
\hline $\begin{array}{l}\text { Min. national accident } \\
\text { rate (per } 1000 \text { workers) }\end{array}$ & $60^{2} ; 54^{3}$ & $70^{4} ; 54^{3}$ & 70 & 29 & 29 \\
\hline $\begin{array}{l}\text { Gross domestic product } \\
\left(\times 10^{6} €\right)\end{array}$ & $\begin{array}{l}3,210^{1} \\
1,532^{2}\end{array}$ & 2,695 & 4,908 & 14,030 & 872 \\
\hline
\end{tabular}

${ }^{1}$ Industry sector, ${ }^{2}$ construction sector, ${ }^{3}$ extraction industry, ${ }^{4}$ metallurgic industry, ${ }^{5}$ chemical industry.

obtained considering the maintenance interval that minimises the life cycle impacts for each design. It can be observed that among the alternatives that base their durability performance on the concrete mix, those that require greater maintenance, namely the baseline alternative 'REF' and the one based on polymers 'PMC10', are those that incur in greater life cycle costs. It can be seen that their maintenance costs are up to four times as much as the construction costs.

However, the final life cycle costs do not strictly depend on the amount of maintenance operations required but on the costs associated to them. This is the case of the design based 




Figure 1: Life cycle cost assessment results.

on the application of surface treatments, which is the most maintenance demanding alternative. However, as this alternative does not require the concrete cover to be demolished and regenerated, the costs associated to each repair are almost negligible in comparison to the rest. Consequently, although it is the most maintenance demanding solution, its associated life cycle costs are the most preferable among the other alternatives.

In line with the above, it is also interesting to note that the alternative with no maintenance needs INOX shows by far not the best life cycle performance in economic terms, as its great construction costs almost double the life cycle costs of other alternatives, such as HYDRO or SF10.

\subsection{Environmental performance results}

Environmental impacts associated to the construction of each alternative are presented in Fig. 2. In general terms, the impact on the ecosystems is shown to be almost negligible when compared with the impacts on the human health or the availability of resources. It is observed that the construction phase impacts the environment almost the same irrespective of the design chosen, except for the use of stainless steel. For this case, the construction impacts are three times greater than for the rest of the alternatives. In particular, it is observed that such result is mostly affected by the impact that the production of stainless steel has on the resources depletion. In this study, the Ecoinvent concept 'steel production, chromium steel $18 / 8$, hot rolled - RER' has been used to approximate the impacts of stainless-steel produc-

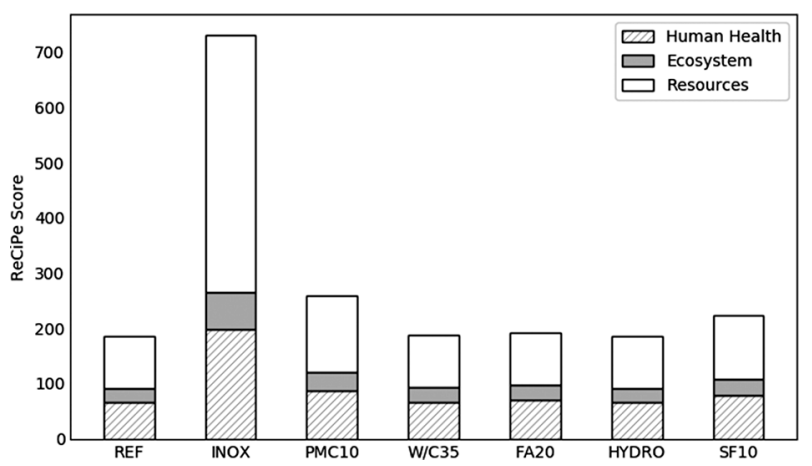

Figure 2: Environmental impacts during construction. 


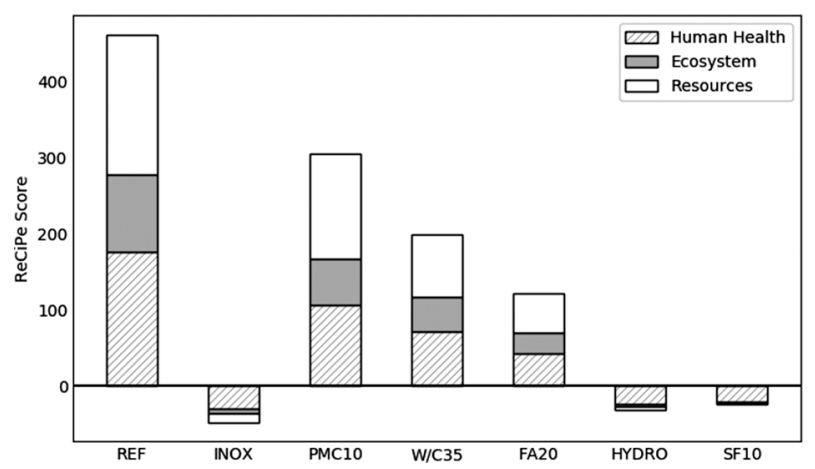

Figure 3: Environmental impacts during maintenance phase.

tion. It shall be noted that, in this study, it has been assumed that no scrap metal is recycled for the production of stainless steel, which would partially reduce the results obtained for this alternative.

Figure 3 presents the environmental impacts derived from the maintenance phase of each alternative. Similar conclusions as for the economic assessment shall be drawn here: for concrete-based durability, the greater maintenance the more impact on the environment. Again, this is valid when maintenance implies concrete cover demolition and concrete production. Here, negative results are observed for the alternatives INOX, SF10 and HYDRO. This results from the positive impact on the environment associated to the carbonation of concrete [27].

\subsection{Social performance results}

Here, results are presented on the social life cycle impacts of each alternative. Figure 4 shows the impacts derived from the construction phase. It shall be noted that only the impacts on workers and on the economic regional development are evaluated during construction. This results from considering every alternative to require the same construction time, thus leading to exactly the same impacts on the public opinion for every alternative. Impacts on the public opinion during construction are, therefore, not presented here, as they do not provide useful information for the comparison of alternatives. On the other hand, and by definition, the impacts on users are only related to the later maintenance and use stage.

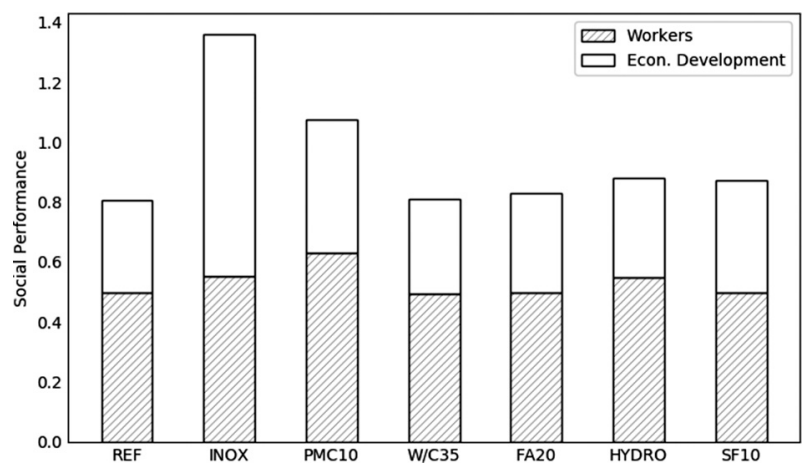

Figure 4: Social performance results during construction. 


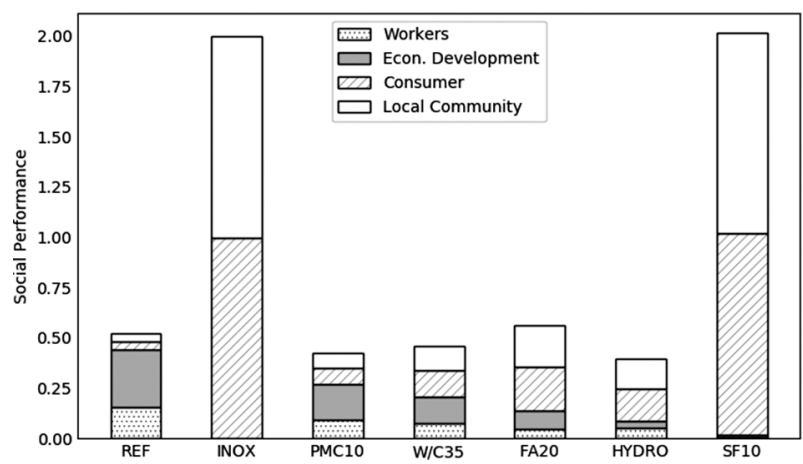

Figure 5: Social performance results during maintenance phase.

It is observed that the positive impact on workers during construction is very similar between alternatives. The great difference lies here on the economic development of regions. In particular, this positive impact is significantly greater for the alternative INOX than for every other alternative. This is related to the important economic inflow to the region producing stainless steel derived from the high cost associated to this material.

Figure 5 presents the social impacts associated to the maintenance and use stage, and it is observed that the greatest social impact results from the alternatives with the lowest maintenance needs, namely INOX and SF10. As those solutions incur in very few or no maintenance along their service lives, the travel safety and accessibility of users, as well as the public opinion of the local community, are not affected by them, thus resulting in those two sub-categories scoring the most.

Regarding the economic development of regions, it shall be noted that the baseline alternative REF is the one with the greatest performance, followed by alternative PMC10. This is related to the great maintenance operations required by these solutions. Consequently, the associated high concrete production demands to maintain these alternatives in service derives in also high economic inflows to the concrete production centres. On the contrary, the alternative HYDRO is the one with the lowest social performance, although scoring more in the subcategories users and public opinion than other alternatives such as REF, PMC10 or $\mathrm{W} / \mathrm{C} 35$. This is due to the fact that the application of hydrophobic surface treatments requires less workers and less time than those other solutions involving concrete cover replacement. Additionally, the economic expenses are also reduced for this alternative, as has been discussed earlier. Consequently, the reduced employment generation and the reduced economic inflows.

\subsection{Economic-environmental vs social-sustainability assessment}

Here, the performance results of each alternative for each sustainability dimension are aggregated into two different sustainability approaches, namely a conventional economic-environmental, two-dimensional approach and a three-dimensional approach including the social dimension as well. The multi-criteria decision-making technique TOPSIS [28] has been used to aggregate the results. The weights for each impact category result from applying the Analytic Hierarchy Process [29], involving a group of three experts. Table 6 shows the resulting relevance associated to each category. It is observed that when it comes to assessing 
Table 6: Criteria relevance for 2D and 3D assessment approaches.

\begin{tabular}{lll}
\hline Criterion & $\begin{array}{l}\text { Economic-environmen- } \\
\text { tal approach }\end{array}$ & Holistic approach \\
\hline Construction costs & $8.2 \%$ & $6.2 \%$ \\
Maintenance and end-of-life costs & $5.7 \%$ & $4.3 \%$ \\
Damage to human health & $25.7 \%$ & $19.5 \%$ \\
Damage to ecosystem & $30.1 \%$ & $22.8 \%$ \\
Resource availability & $30.3 \%$ & $22.9 \%$ \\
Workers & - & $3.8 \%$ \\
Economic development of regions & - & $3.6 \%$ \\
Users & - & $9.5 \%$ \\
Public opinion & - & $7.4 \%$ \\
\hline
\end{tabular}

sustainability, great importance is given to environmental criteria, summing up to $86.1 \%$ in the case of the 2D approach and up to $65.2 \%$ in the case of the 3D approach. In the holistic approach, the relative importance of the social dimension reaches a $24.3 \%$.

Figure 6 shows the life cycle sustainability performance of each alternative under study assuming an economic-environmental approach. Results are presented for the construction stage, as well as for the maintenance and demolition stage (RoL). For each assessment dimension, namely economy and environment, the impact associated to both the construction and the service stage is shown. The maintenance interval for each alternative has been obtained that maximises the resulting sustainability score based on the optimisation procedure described earlier. For representation purposes, results for each dimension are provided relative to the impacts of the alternative with the greatest impact. As presented earlier, these alternatives are REF for economic impacts and INOX for the environmental dimension.

As has been discussed earlier, this is derived from the great number of highly impacting maintenance operations required by them. However, it is noteworthy that the maintenance-free alternative INOX performs almost the same than the baseline solution, which is the least

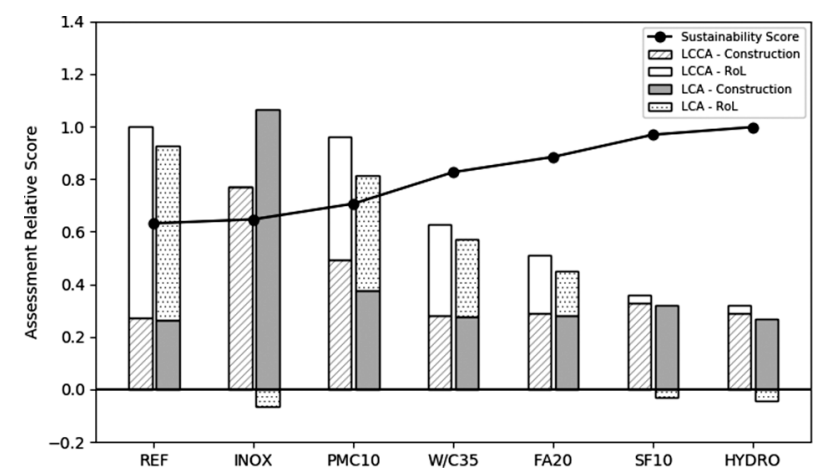

Figure 6: Sustainability assessment results considering only the economic and the environmental dimensions. 


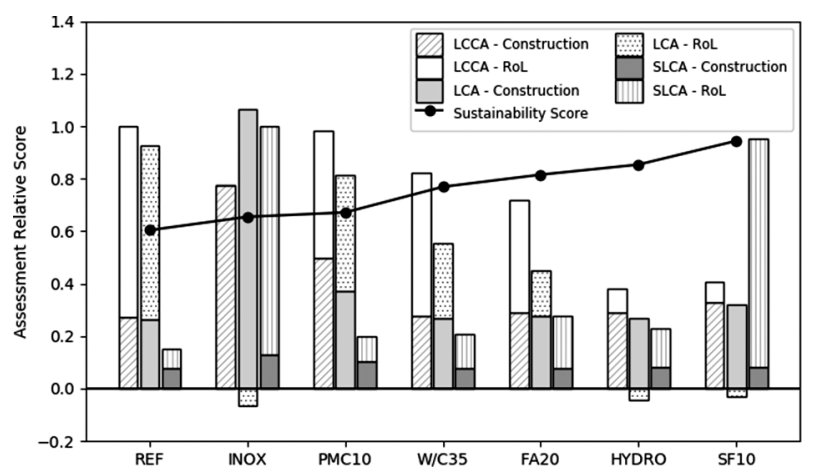

Figure 7: Sustainability assessment results including the social dimension.

preferable design among the rest. Consequently, although playing an essential role in conventional designs basing their durability in concrete resistant mixes, great maintenance needs do not always mean less sustainability.

The results obtained for HYDRO alternative support this statement, as HYDRO is the alternative with the greatest maintenance needs but is also the solution that scores the best in this two-dimensional sustainability assessment.

Figure 7 shows the sustainability results including the social dimension in the assessment. Results are presented for the construction stage, as well as for the maintenance and demolition stage (RoL). Again, results are presented in relative terms with regard to the alternative that results in the greatest impact for each dimension, namely REF for the economic dimension and INOX for the environmental and the social one. The best performing alternative considering this approach is the one based on the use of silica fume addition. This solution is a fairly balanced design, which works very well in terms of durability, although it does not score best on any of the different dimensions of sustainability separately.

The sustainability score for SF10 solution is $11 \%$ greater than the one derived from the alternative based on the use of hydrophobic surface treatments, which performed best in the conventional, two-dimensional approach. This shows that the inclusion of the social dimension in sustainability assessments may lead to the choice of solutions that can be neglected when performing conventional assessments.

\section{CONCLUSIONS}

In this article, an ISO14040-based, three-dimensional life cycle assessment is performed regarding seven different design alternatives for a prestressed concrete bridge in a coastal environment. The analysis considers economic, environmental and social impacts associated to the construction and the maintenance of the structure. A service life of 100 years has been assumed. Results have been presented and discussed regarding the impacts on each of the three sustainability dimensions. In addition, the multi-criteria decision-making technique TOPSIS has been applied to evaluate the resulting sustainability performance of each alternative, comparing results for a conventional economic-environmental approach and for a holistic, three-dimensional approach including the social dimension.

In general terms, increasing the durability performance in aggressive environments leads to better sustainability results. However, this conclusion only applies when considering solutions that base their durability on enhancing the baseline concrete mix. It has been observed that when including other types of durability design strategies, such as the use of non-con- 
ventional steels or the use of surface treatments, neither low maintenance always results in greater sustainability scoring nor highly maintenance-demanding solutions cannot perform well. It has been shown how maintenance-free solutions such as those based on stainless steel perform far worse than the highly maintenance demanding solution based on the periodically reapplication of hydrophobic surface treatments.

The social dimension has been proved to play a relevant role when it comes to sustainable design of structures. Although usually disregarded, this article shows that including the social dimension effectively in the sustainability life cycle assessment of maintenance demanding structures, such as concrete bridges in aggressive environments, shall result in better performing designs than those that would have resulted from conventional two-dimensional analyses. So, while the conventional approach has resulted in hydrophobic surface treatments to be the preferable solution, including social aspects in the assessment has resulted in concrete with silica fume additions to perform $11 \%$ better in terms of sustainability.

\section{ACKNOWLEDGEMENTS}

The authors acknowledge the financial support of the Spanish Ministry of Economy and Competitiveness, along with FEDER funding (Project: BIA2017-85098-R).

\section{REFERENCES}

[1] Choi, J., Strategy for reducing carbon dioxide emissions from maintenance and rehabilitation of highway pavement. Journal of Cleaner Production, 209, pp. 88-100, 2019. https://doi.org/10.1016/j.jclepro.2018.10.226

[2] Huang, M., Zhang, X., Ren, R., Liao, H., Zavadskas, E.K. \& Antucheviciene, J., Energy-saving building program evaluation with an integrated method under linguistic environment. Journal of Civil Engineering and Management, 26(5), pp. 447-458, 2020. https://doi.org/10.3846/jcem.2020.12647

[3] Kyriacou, A., Muinelo-Gallo, L. \& Roca-Sagalés, O., The efficiency of transport infrastructure investment and the role of government quality: An empirical analysis. Transport Policy, 74, pp. 93-102, 2019. https://doi.org/10.1016/j.tranpol.2018.11.017

[4] Payá-Zaforteza, I., Yepes, V., González-Vidosa, F. \& Hospitaler, A., On the Weibull cost estimation of building frames designed by simulated annealing. Meccanica, 45(5), pp. 693-704, 2010. https://doi.org/10.1007/s11012-010-9285-0

[5] Hasan, M.A., Yan, K., Akiyama, M. \& Frangopol, D.M., LCC-based identification of geographical locations suitable for using stainless steel rebars in reinforced concrete girder bridges. Structure and Infrastructure Engineering, 16(9), pp. 1201-1227, 2020. https://doi.org/10.1080/15732479.2019.1703758

[6] Molina-Moreno, F., García-Segura, T., Martí, J.V. \& Yepes, V., Optimization of buttressed earth-retaining walls using hybrid harmony search algorithms. Engineering Structures, 134, pp. 205-216, 2017. https://doi.org/10.1016/j.engstruct.2016.12.042

[7] Navarro, I.J., Martí, J.V. \& Yepes, V., Reliability-based maintenance optimization of corrosion preventive designs under a life cycle perspective. Environmental Impact Assessment Review, 74, pp. 23-34, 2019. https://doi.org/10.1016/j.eiar.2018.10.001

[8] Xin, J., Akitama, M., Frangopol, D.M., Zhang, M., Pei, J. \& Zhang, J., Reliabilitybased life-cycle cost design of asphalt pavement using artificial neural networks. Structure and Infrastructure Engineering, 2020.

[9] Molina-Moreno, F., Martí, J.V. \& Yepes, V., Carbon embodied optimization for buttressed earth-retaining walls: implications for low-carbon conceptual designs. 
Journal of Cleaner Production, 164, pp. 872-884, 2017. https://doi.org/10.1016/j. jclepro.2017.06.246

[10] Torres-Machi, C., Pellicer, E., Yepes, V. \& Chamorro, A., Towards a sustainable optimization of pavement maintenance programs under budgetary restrictions. Journal of Cleaner Production, 148, pp. 90-102, 2017. https://doi.org/10.1016/j. jclepro.2017.01.100

[11] García-Segura, T., Yepes, V. \& Frangopol, D.M. Multi-objective design of post-tensioned concrete road bridges using artificial neural networks. Structural and Multidisciplinary Optimization, 56(1), pp. 139-150, 2017. https://doi.org/10.1007/s00158-017-1653-0

[12] Penadés-Plà, V., Martí, J.V., García-Segura, T. \& Yepes, V. Life-cycle assessment: A comparison between two optimal post-tensioned concrete box-girder road bridges. Sustainability, 9(10), p. 1864, 2017. https://doi.org/10.3390/su9101864

[13] Navarro, I.J., Yepes, V. \& Martí, J.V., Social life cycle assessment of concrete bridge decks exposed to aggressive environments. Environmental Impact Assessment Review, 72, pp. 50-63, 2018. https://doi.org/10.1016/j.eiar.2018.05.003

[14] Sierra, L.A., Pellicer, E., \& Yepes, V. Method for estimating the social sustainability of infrastructure projects. Environmental Impact Assessment Review, 65, pp. 41-53, 2017. https://doi.org/10.1016/j.eiar.2017.02.004

[15] Gervásio, H., \& da Silva, L.S., Life-cycle social analysis of motorway bridges. Structure and Infrastructure Engineering, 9(10), pp. 1019-1039, 2013. https://doi.org/ 10.1080/15732479.2011.654124

[16] Wang, W., On fuzzy TOPSIS method based on alpha level sets. Journal of Intelligent \& Fuzzy Systems, 33(6), pp. 4067-4076, 2017. https://doi.org/10.3233/jifs-17983

[17] Jia, J., Ibrahim, M., Hadi, M., Orabi, W. \& Xiao, Y., Multi-criteria evaluation framework in selection of Accelerated Bridge Construction (ABC) method. Sustainability, 10, p. 4059, 2018. https://doi.org/10.3390/su10114059

[18] Pipinato, A., Rebelo, C., Pedrosa, B. \& Gervásio, H., Assessment procedure and rehabilitation criteria for riveted road bridges. Structural Engineering International, 30(1), pp. 109-118, 2020. https://doi.org/10.1080/10168664.2019.1615855

[19] Navarro, I.J., Penadés-Plà, V., Martínez-Muñoz, D., Rempling, R. \& Yepes, V., Life cycle sustainability assessment for multi-criteria decision making in bridge design: A review. Journal of Civil Engineering and Management, 26(7), pp. 690-704, 2020. https://doi.org/10.3846/jcem.2020.13599

[20] UNEP/SETAC. Guidelines for Social Life Cycle Assessment of Products. United Nations Environment Program. In: Paris SETAC Life Cycle Initiative United Nations Environment Programme, 2009.

[21] Fib. Fib Bulletin 34: Model Code for Service Life Design. Fib, Lausanne, 2006.

[22] Nogueira, C.G., Leonel, E.D. \& Coda, H.B., Reliability algorithms applied to reinforced concrete structures durability assessment. Revista IBRACON de Estruturas e Materiais, 5(4), pp. 440-450, 2012. https://doi.org/10.1590/s1983-41952012000400003

[23] Navarro, I.J., Yepes, V. \& Martí, J.V., Role of the social dimension on the sustainabilityoriented maintenance optimization of bridges in coastal environments. WIT Transactions on The Built Environment, Vol. 196, WIT Press, 2020, ISSN 1743-3509.

[24] Goedkoop, M., Heijungs, R., Huijbregts, M., De Schryver, A., Struijs, J. \& Van Zelm, R., 2009. ReCiPe 2008, First Edition. (Report I: Characterisation) 
[25] UNEP/SETAC. The methodological sheets for subcategories in social life cycle assessment (S-LCA). UNEP-SETAC Life-Cycle Initiative, Paris, France, 2013.

[26] Ecoinvent 3.2 database, www.ecoinvent.org. Accessed on: October 2020.

[27] Navarro, I.J., Yepes, V., Martí, J.V. \& González-Vidosa, F., Life cycle impact assessment of corrosion preventive designs applied to prestressed concrete bridge decks. Journal of Cleaner Production, 196, pp. 698-713, 2018. https://doi.org/10.1016/j. jclepro.2018.06.110

[28] Hwang, C.L., \& Yoon, K., Multiple Attribute Decision Making: Methods and Applications. New York: Springer-Verlag, 1981.

[29] Saaty, T.L., The Analytic Hierarchy Process: Planning, Priority Setting, Resource Allocation, McGraw-Hill., 1980. 